\title{
PROJECT-DRIVEN HETERARCHY: AN EMPIRICAL STUDY ON PROJECT TEAMS' LEARNING ABILITIES AND CREATIVITY
}

\author{
Janusz Marek Lichtarski \\ Institute of Organization and Management, Wrocław University of Economics, Poland
}

\begin{abstract}
A growing body of research shows that projects' success require a high level team learning abilities and creativity. Since project-based organizations are constructed on the basis of different set of principles and mechanisms than hierarchical ones, the relationships between heterarchy and learning abilities and creativity of project teams seems to be critical. The paper aims to contribute to the current research on project structures. Specifically, the aim of the paper is to present the results of the questionnaire research on the team learning abilities and creativity in project-based organizations. The study was performed on 370 teams represented by line managers $(n=102)$, project managers $(n=122)$, and project team members $(n=146)$. The study depicts correlations between intensity of heterarchy, and the level of learning abilities and creativity perceived by managers and project team members (non-managers).
\end{abstract}

Key words: Project management, project structure, heterarchy, learning abilities, creativity.

\section{INTRODUCTION}

Projects understood as temporary, complex and unique endeavors, require a high level of learning abilities and creativity of teams involved, and a growing body of research in project management link mentioned features with project success, especially in $R \& D$ and innovative projects. However, one of the critical factor of developing team learning abilities and creativity is organizational structure. Regardless of project structures type, i.e. functional structure with project managers, project matrix, or pure project structure, they all are built on another set of principles that traditional hierarchies: project teams are temporary, cross-functional, and co-exist with stable organizational units (Jenny, 2007; Kerzner, 2009; Kousholt, 2007; Lock, 2014). Unity of command is undermined, and hierarchy is replaced with multiple and transitive power - a heterarchy. The research question that arise: Do heterarchy, being the basic coordination mechanism of all types of project structures, enhances team learning abilities and creativity?

It is worth to be mentioned that the stable hierarchy has been the basic mechanism of integration and coordination of people's activities for centuries. In management science, it was one of the main principles of management stressed by representatives of scientific management and administrative approach, e.g. Taylor, Fayol, Weber, etc. Nevertheless, in the middle of the twentieth century, the disadvantages of hierarchical organizations became to be noticed, especially in organizations operating in complex and unstable environment (Burns, \& Stalker, 1961; Lawrence, \& Lorsch, 1967), and in multinational corporations (Bartlett, \& Ghoshal, 1989; Prahalad, 1976). Hence, the attempts to seek alternative mechanisms of integrating and coordinating actions were made what resulted in development of the idea of heterarchy (Hedlund, 1986). Although the heterarchy was described three decades ago, it is still not exhaustively recognized and constitutes quite rare research subject. Simultaneously, it is worth emphasizing that as a result of development of project structures, multiple and transitive power becomes an inevitable part of contemporary management practice.

The heterarchy can be analyzed at three levels: inter-, meso-, and intra-organizational. At the inter-organizational level of analysis the

Corresponding author. Email: janusz.lichtarski@ue.wroc.pl

ISSN 2560-4961(online)

(C) 2018 IPMA Serbia

doi: 10.18485/epmj.2018.8.1.2 
research subject concerns the relationships between independent enterprises, nodes of inter-organizational network. Due to the mesolevel analysis, the relationships between divisions of large corporations are crucial, and according to the intra-organizational analysis level, the research subject is associated with the relationships amongst individuals within a team or group. While the research results concerning two first levels of analysis have been presented in various studies (Birkinshaw, \& Morrison, 1995; Ghoshal, \& Bartlett, 1990; Hedlund, 1986; Hedlund, 1994), the intraorganizational level analysis reveals an interesting research gap.

Presented research is important at least for two reasons. First, it pays attention to complex and dynamic phenomenon of heterarchy, which is an inevitable part of project structures, and both scholars and practitioners have limited knowledge about it. Second, previous studies on project structures' and heterarchy focus on managerial perspective, while the team members' point of view seems to be underestimated. Presented study in contrary presents both perspectives.

The paper is organized as follows. The first part presents theoretical background of the heterarchy as a part of project structures. It also illustrates the role of team learning abilities and creativity in successful project management. Next sections presents research method, results of the study, and also discussion and conclusion.

\section{THEORETICAL BACKGROUND}

\subsection{From hierarchy to heterarchy}

The hierarchy was the dominating mechanism of integrating and coordinating activities for decades (Leavitt, 2005). The first references about heterarchy in the management sciences appeared in the nineteen eighties. The hallmarks and research associated with heterarchy refer to the various contexts, e.g. multi-national corporations (Birkinshaw, \& Morrison, 1995; Hedlund, 1986), knowledge management (Hedlund, 1994), creativity of interdisciplinary teams (Aime, Humphrey, Derue, \& Paul, 2014), or formulating a strategy in an organization (Chakravarthy, \& Henderson, 2007).
The most disseminated context of exploring heterarchy in studies, begun by Hedlund (1986), concerns the relationships between divisions in large multi-national corporations. This approach is located in the mesoorganizational perspective as it discerns relationships between entities of a large enterprise. At the same time much little attention has been paid to intra-organizational level. The analysis of multiple and dynamic power at the intra-organizational level acquires growing importance as a result of project management development, and dissemination of project structures.

Heterarchy has been included in theoretical considerations and empirical studies rarely since hierarchical thinking in perceiving the world is dominant, and permanent hierarchy is strongly embedded in a human nature and way of thinking (Simon, 1969). It impedes scholars to recognize more complex forms, like the heterarchy. The next reason for undervaluing the heterarchy is a dominant position of hierarchy in business practice. Despite numerous expectations in terms of abandoning hierarchies in favor of fluid structures (see e.g. Dillow, 2007; Handy, 1994; Peters, 1989; Toffler, 1970), hierarchy is still dominant (Ashkenas, Ulrich, Jick, \& Kerr, 2002; Leavitt, 2005). Nevertheless, despite hierarchy domination, heterarchical coordination becomes more and more common, especially in project-based organizations, both business (Stark, 2009; Stephenson, 2009) and public ones (Espinosa, Harnden, \& Walker, 2007). Multiple and transitive power is present in all organizations where temporary project teams, work groups or task forces are formed to complete complex tasks and projects.

\subsection{Project-driven heterarchy}

Hedlund (1986) defines heterarchy as multiplicity and transitivity of power. It means that many authority centers exist simultaneously (dispersion of power), as well as that the power is unstable (transitivity of power). Intentional abandoning the principle of unity of direction is accompanied by unstable status of particular organizational units and relations amongst them.

Fairtlough (2007) describes heterarchy as multiple and balanced power in an organization 
and he distinguishes it strongly from singular and stable hierarchy. The author explains the balance in executing power in heterarchical systems using analogy to the paper, scissors, and stone game, where none of elements is dominant from the nature.

As each team action must be ordered and organized, heterarchy is a set co-existing and unstable relations of subordination in an organization. Heterarchy constitutes a basic mechanism of integrating and coordinating actions of those who participate in various project structures: project matrix, functional structure with project managers/coordinators, projectized structure, etc. Stephenson (2009) locates heterarchy between hierarchy and network. A heterarchy can vary in its presence from low to high depending on the number of authority centers, and theirs stability. The more authority centers, and the more frequent power changes, e.g. short-time projects, changes of project manager or coordinator during project execution, etc., the higher level of heterarchy.

Concluding, independently on a way of executing projects in an organization, convening temporary project teams means abandoning the principle of unity of direction, multiplying power centers, and distorting a stable hierarchy, which is substituted by more complex and fluent heterarchical coordination.

\subsection{Learning abilities and creativity as desirable characteristics of project-based organizations}

Some studies show that knowledge gained from previous projects is shared with emerging project teams not effectively (Ajmal \& Koskinen, 2008; Newell, Bresnen, Edelman, Scarbrough, \& Swan, 2006), and on the other hand the role of team learning abilities and creativity in project success and organizational outcomes seems to be unquestionable (Algeo, 2014; Anbari, Carayannis, \& Voetsch, 2008; Juli, 2011; Kelley, 2000; Newell, \& Edelman, 2008; Nonaka, \& Takeuchi, 1995). It concerns both individuals, and project teams where mentioned characteristics are more related to systemic solutions, e.g. project learning practices, organizational leaning factors, group problem solving techniques, etc., than individual, psychological conditions. The need for high learning abilities of project teams results from complexity of projects, while creativity from its unique nature. A high level of team learning abilities means quick gaining knowledge from previous projects and own mistakes, sharing knowledge within the team, developing effective practices, etc. (Koskinen, 2012; Newell, et al., 2006). A high level of creativity means coping with uncertainty, easiness in solving non-standardized problems, and ability to introduce innovations (Kelley, 2000).

Since mentioned team abilities are strongly dependent on organizational design (Koskinen, 2012), to enhance learning abilities and knowledge sharing Nonaka (1994) proposed the idea of hypertext structure which blends the strengths of stability and standardization with flexibility and dynamism of task forces. It combines three layers: the business system layer, the project team layer, and the knowledge base layer. Due to its complexity and dynamic nature, the concept is based on heterarchical coordination.

\section{RESEARCH METHODS}

To answer the research question, the questionnaire research has been conducted amongst managers and non-managers. It has been envisaged that the hypotheses will be verified positively if statistically significant correlation between presented variables is ascertained. The results presented in the paper are the part of the wider research project on heterarchy, including the compilation of various research methods and techniques. One of initial research methods used was cross-case study research design. The longitudinal and deepened field study in six various organizations proved that the causality between investigated variables could be complex and mutual: on the one hand heterarchy influence team learning abilities and creativity, and on the other hand team learning abilities and creativity create conditions for developing heterachical coordination. Regardless of the direction of relationships studied the question of correlation between variables in large sample study arises.

The intensity of heterarchy was described by its two dimensions, derived from its definition: a) multiplicity of power, and b) transitivity of 
power. Both intensity of heterarchy in a team environment, and team learning abilities and creativity, were identified on the basis on set of descriptive questions with statements and 5 grade Likert-type scales.

The research sample included 370 teams represented by: 28 top level managers (general directors, divisional directors, department directors, branch directors), 74 middle level managers (managers of departments, sections, teams), 122 project managers, and 146 specialists (team members, contractors). ${ }^{1}$ Data analyses were performed by the means of IBM SPSS software with an alpha level set to .05. In order to examine non-causal relationship between variables and regarding the type of scales, Spearman's rank correlation coefficient has been used. The research was being conducted from 2015 to 2016.

\section{RESULTS}

The research results have been compared between two groups. The first group constitutes both line and project managers. ${ }^{2}$ The second group involves non-managers: specialists, team members, etc. The values of the Spearman's rank correlation coefficient for managers and non-managers are presented in Table 1.

Table 1: Correlations between intensity of heterarchy, and team learning abilities and creativity

\begin{tabular}{|l|l|l|c|c|c|c|}
\hline \multicolumn{2}{|c|}{} & \multicolumn{2}{|c|}{ Managers } & \multicolumn{2}{c|}{ Non-managers } \\
\hline \multicolumn{2}{|c|}{} & $\begin{array}{c}\text { Team } \\
\text { learning } \\
\text { abilities }\end{array}$ & $\begin{array}{c}\text { Team } \\
\text { creativity }\end{array}$ & $\begin{array}{c}\text { Team } \\
\text { learning } \\
\text { abilities }\end{array}$ & $\begin{array}{c}\text { Team } \\
\text { creativity }\end{array}$ \\
\hline $\begin{array}{l}\text { Spearman's } \\
\text { rho }\end{array}$ & $\begin{array}{l}\text { Multiplicity } \\
\text { of power }\end{array}$ & $\begin{array}{l}\text { Correlation } \\
\text { coefficient }\end{array}$ & $\mathbf{, 1 8 4}$ &,- 015 &, 076 &,- 075 \\
\cline { 3 - 7 } & $\begin{array}{l}\text { p-value } \\
\text { (two- } \\
\text { tailed) }\end{array}$ & $\mathbf{, 0 0 9}$ &, 827 &, 390 &, 398 \\
\cline { 3 - 7 } & $\mathbf{N}$ & $\mathbf{2 0 0}$ & 202 & 129 & 129 \\
\cline { 2 - 7 } & $\begin{array}{l}\text { Transitivity } \\
\text { of power }\end{array}$ & $\begin{array}{l}\text { Correlation } \\
\text { coefficient }\end{array}$ &, 126 &,- 074 &, 039 &,- 011 \\
\cline { 3 - 7 } & $\begin{array}{l}\text { p-value } \\
\text { (two- } \\
\text { tailed) }\end{array}$ &, 076 &, 298 &, 663 &, 903 \\
\cline { 2 - 7 } & $\mathrm{N}$ & 200 & 202 & 130 & 131 \\
\hline
\end{tabular}

Source: authors' own

The statistically significant association between the multiplicity of power and team learning abilities in the managers group answers' was observed. The relationships is positive, what means that the more power centers exist at the same time, the higher level of team learning abilities perceived by

\footnotetext{
${ }^{1}$ Examined teams represented international/global corporations of various industries, e.g. IT industry (IBM, Nokia, HP, Wincor-Nixdorf, Volvo IT, Unity), automotive (VW, Volvo, Scania, Wabco, Toyota, Draexmaier, Faurecia, Sitech, Leoni), construction (MotaEngil, Skanska, Selena, Atlas), pharmaceutical (GSK), financial (Catlin, Xelion, Pekao, Credit Suisse, Santander Consumer Bank), electronic (LG Electronics), consulting (McKinsey, EY), and FMCG (Purina, Jeronimo Martins). This is important for conclusions and
}

managers. No other significant correlations between studied variables were observed both in managers, and non-managers groups.

The relationships between studied variables, i.e. multiplicity and transitivity of power as well as, and team learning abilities and

generalizations of the results. The number of answers in each section are different from the total size of the research sample, due to incompleteness and incorrectness of answers.

2 Significant differences in the group of line managers (all levels) and project managers' answers have not been observed. Consequently, despite distinguishing some sub-groups, the research results are analysed for all managers together. 
creativity, seem to be mutual and causality is not clear in this case. On the one hand, heterarchy influences creativity and team learning abilities, and on the other hand, creativity, and learning abilities may create conditions for the development of heterarchical coordination. That was the reason why Spearman's correlation coefficient was used. As the correlation between variables is weak (Table 1), and the relationships are complex and mutual, other statistical tests can be misleading. A more deepened study, based on various techniques of data collection, is required to investigate studied explored relationships and causality thoroughly.

\section{DISCUSSION}

Project structures meaningfully differ from stable organizational pyramids, and dynamic heterarchy is a different from a permanent hierarchy. According to teams having been examined, multiplicity and transitivity of power was a result of conducting different type of projects. The separate analysis of two selected heterarchy dimensions, i.e. multiplicity and transitivity of power, concerning two groups: managers and nonmanagers has authorized to formulate the following ascertainment. First, multiplicity of power was positively correlated with team learning abilities, but only in managerial perspective. The reasons of differences between managers, and non-managers groups answers' may be as follow: a) managers underestimate positive effects of heterarchical conditions, or b) team members are not conscious and do not have enough knowledge concerning team learning abilities or creativity (focused on executing task do not observe knowledge development etc.). Those questions require further studies basing on objective data, e.g. project team performance, project benchmark analysis etc., and deepened qualitative research methods: longitudinal cross-case study, and action research.

Associating the results with prior studies on heterarchy (Aime, et al., 2014; Nonaka, 1994; Schnetler, Steyn, \& van Staden, 2015), some disagreement about its advantages in terms of team learning and creativity occurs. One of the reasons for differences observed may be related to level of analysis. Referenced authors had not investigate the intensity or strength of heterarchy, but only its presence. Presented approach, based rather on continuum of heterarchy than dichotomy, seems to be more accurate (e.g. studied relationships can be an inverted-U relationships). The other reason that no strong advantages of heterarchy in terms of learning and creativity were identified in the study, may be related to unsafety and uncertainty perceived both by managers, and team members (Greiner, \& Schein, 1981; Katz, $\&$ Allen, 1985). The high level of uncertainty and unsafety, resulting from heterarchy, may influence team learning and creativity negatively, and that is one of the reasons for maintain the stable business layer in Nonaka's (1994) hypertext structure.

The presented findings are not free of limitations. Some of them are characteristic to questionnaire issues, e.g. potential differences of understanding and interpreting given questions, or the influence of respondents' point of view, earlier experience, etc. Another type of limitations is related to low comparability of results. The difficulties in comparing results among researchers and replicability as a result come from: a) unique nature of projects (incomparability of projects), 2) dissimilarity of teams examined, 3) situational and time-related context, and 4) various research methods used in conducted studies. The future directions in research on project-based heterarchy concern searching for mechanisms of developing project teams' creativity and learning abilities in heterarchical environment. A deepened investigation requires longitudinal study, based on the cross case study research design (Gerring, 2007) and multiple methods of data collections (documentation, interviews, as well as experiments and simulations). On the other hand, a very interesting and promising future direction in the research on heterarchy and its implications is the exploration of industryrelated, and culture-related contexts in a wide international study.

\section{CONCLUSION}

Despite scholars' theoretical considerations in the scope of heterarchy, there is still considerable ambiguity surrounding that construct. The results obtained do not provide strong fundamentals for verifying research hypotheses positively. Only the hypothesis H1 
is justified to be verified, and only partially: moderate positive correlation between multiplicity of power and team learning abilities in managers group. It is worth taking into account that the research on heterarchy phenomenon is a challenge what confirms even the definition of heterarchy, i.e. it is a complex and changeable phenomenon what considerably hinders operationalizing that construct. Provided that the multiplicity of power can be noticed in static studies, identifying the transitivity of power authority requires a dynamic perspective or deepened retrospective analysis.

Despite moderate values of the correlation coefficient, difficulties in determining the casualty, and limitations in terms of verifying hypothesis, the research seems to be recognized as innovative. The research results reveal both theoretical and practical salience as well as an important research direction in the project management approach. A well designed project-based organization is one of key success factors (Roberts, 2012). The key result raises the issue of co-existing two different perspectives on heterarchy: managerial and non-managerial one.

\section{REFERENCES}

Aime, F., Humphrey, S., Derue, D. S., \& Paul, J. B. (2014). The Riddle of Heterarchy: Power Transitions in Cross-Functional Teams. Academy of Management Journal, 7(2), 327-352.

Ajmal, M. M., \& Koskinen, K. U. (2008) Knowledge transfer in project-based organizations: An organization culture perspective, Project Management Journal, 39, 1, 7-15

Algeo, C. (2014). Exploring Project Knowledge Acquisition and Exchange Through Action Research. Project Management Journal, 45 (3), 46-56.

Anbari, F. T., Carayannis, E. G., \& Voetsch, R. J. (2008) Post-project reviews as a key project management competence, Technovation, 28, 633-643

Ashkenas, R., Ulrich, D., Jick, T., \& Kerr, S. (2002). The Boundaryless Organization. Breaking The Chains of Organizational Structure. Jossey-Bass, San Francisco.
Bartlett, C. A., \& Ghoshal, S. (1989). Managing Across Borders: The Transitional Solution. Harvard Business School Press, Cambridge.

Birkinshaw, J. M., \& Morrison, A. J. (1995). Configuration of Strategy and Structure in Subsidiaries of Multinational Corporations. Journal of International Business Studies, 26(4), 729-753.

Burns, T., \& Stalker, G. M. (1961). The Management of Innovation. Tavistock Publications, London.

Chakravarthy, B., \& Henderson, J. (2007). From a Hierarchy to a Heterarchy of Strategies: Adapting to a Changing Context. Management Decision, 45 (3), 642-652.

Dillow, C. (2007). The End of Politics: New Labour and the Folly of Managerialism. Harriman House, Hampshire.

Espinosa, A., Harnden, R., \& Walker, J. (2007). Beyond hierarchy: a complexity management perspective. Kybernetes, 36 (3-4), 333-347.

Fairtlough, G. (2007). The Three Ways of Getting Things Done. Hierarchy, Heterarchy, and Responsible Autonomy in Organizations. Triarchy Press, Axminster UK.

Gerring, J. (2007). Case Study Research. Principles and Practices. Cambridge University Press, New York.

Ghoshal, S., \& Bartlett, C. A. (1990). The Multinational Corporation as an Interorganizational Network. The Academy of Management Review, 15(4), 603-625.

Greiner, L. E., \& Schein, V. (1981). The Paradox of Managing a Project Oriented Matrix: Establishing Coherence Within Chaos. CEO Publication.

Handy, C. (1994). The Age of Paradox. Harvard Business School Press, Boston.

Hedlund, G. (1986). The Hypermodern MNCa Heterarchy? Human Resource Management, 25(1), 9-35.

Hedlund, G. (1994). A Model of Knowledge Management and the $\mathrm{N}$-form Corporation. Strategic Management Journal, 15, 7390. 
Jenny, B. (2007). Project Management. Knowledge for a Successful Career. VDF Hochschulverlag, Zürich.

Juli, T. (2011). The five team leadership principles for project success. Paper presented at PMI Global Congress 2011North America, Dallas, TX. Newtown Square, PA: Project Management Institute.

Katz, R., \& Allen, T. (1985). Project performance and the locus of influence in the R\&D matrix. Academy of Management Journal, 28(1), 67-87.

Kelley, T. (2000). The art of innovation. Doubleday, New York.

Kerzner, H. (2009). Project Management. A Systems Approach To Planning, Scheduling And Controlling. John Wiley \& Sons Inc., Hoboken.

Koskinen, K. U. (2012). Organizational Learning in Project-Based Companies: A Process Thinking Approach. Project Management Journal, 43(3), 40-49.

Kousholt, B. (2007). Project Management theory and practice. Narayana Press, Copenhagen.

Lawrence, P. R., \& Lorsch, J. W. (1967). Organization and Environment. Irwin, Homewood.

Leavitt, H. J. (2005). Top-Down. Why Hierarchies Are to Stay and How to Manage Them More Effectively. Harvard Business School Press, Boston Massachusetts.

Lock, D. (2014). The Essentials of Project Management. Gower, Farnham.

Newell, S., Bresnen, M., Edelman, L., Scarbrough, H., \& Swan, J. (2006) Sharing knowledge across projects: Limits to ICT-led project review practices, Management Learning, 37 2, 167-185.

Newell, S., \& Edelman, L. F. (2008) Developing a dynamic project learning and cross-project learning capability: Synthesizing two perspectives, IT Journal, 18, 567-591

Nonaka, I. (1994). A Dynamic Theory of Organizational Knowledge Creation. Organization Science, 5(1), 14-37.

Nonaka, I., \& Takeuchi, H. (1995). The knowledge-creating company. How Japanese companies create the dynamics of innovation. Oxford University Press, Oxford.

Peters, T. (1989). Thriving on Chaos. Handbook for a Management Revolution. Pan Books, London.

Prahalad, C. K. (1976). Strategic choices in diversified MNCs. Harvard Business Review 54(4), 67-78.

Roberts, P. (2012). Strategic Project Management. Creating the Conditions for Success. Kogan Page, London.

Schnetler, R., Steyn, H., \& van Staden, P. J. (2015). Characteristics of matrix structures, and their effects on project success. South African Journal of Industrial Engineering, 26(1), 11-26.

Simon, H. (1969). The Sciences of the Artificial. MIT Press, Cambridge.

Stark, D. (2009). The Sense of Dissonance: Accounts of Worth in Economic Life. Princeton University Press, New Jersey.

Stephenson, K. (2009). Neither Hierarchy nor Network: An Argument for Heterachy. People \& Strategy, 32(1), 4-7.

Toffler, A. (1970). Future Shock. Bantam Books, New York. 